\title{
Longitudinal Mapping of Gyral and Sulcal Patterns of Cortical Thickness and Brain Volume Regain during Early Alcohol Abstinence
}

\author{
Guo-Ying Wang ${ }^{a}$ Traute Demirakca ${ }^{a} \quad J u l i a$ van Eijk ${ }^{a} \quad$ Ulrich Frischknecht ${ }^{b}$ \\ Matthias Ruf ${ }^{a}$ Serhat Ucar ${ }^{a}$ Derik Hermann ${ }^{b}$ Karl Mann ${ }^{b}$ Falk Kiefer $^{b}$ \\ Gabriele Ende ${ }^{a}$ \\ ${ }^{a}$ Department of Neuroimaging and ${ }^{b}$ Addictive Behavior and Addiction Medicine, Central Institute of Mental Health, \\ Medical Faculty Mannheim/Heidelberg University, Mannheim, Germany
}

\section{Key Words}

Cortical thickness - Early alcohol abstinence - Gyri · Sulci .

Subcortical volume

\begin{abstract}
We explored brain volume recovery in terms of cortical thickness (CTh; gyral, sulcal pattern) and surface area (SA), as well as subcortical volume recovery in the first 2 weeks of abstinence in 49 alcohol-dependent patients (ADPs). A widespread reduction of CTh in ADPs at day 1 of abstinence compared to healthy controls, with more pronounced differences in sulci relative to gyri was found. After 2 weeks of abstinence, partial recovery to varying degrees of CTh loss in ADPs was observed for several regions. The longitudinal CTh changes were greater in sulci than in gyri of affected regions. No longitudinal change in SAs and subcortical volumes was found. Alterations of CTh contribute to brain volume loss in alcoholism and recovery during early abstinence. Sulci seem to be more vulnerable to excessive alcohol consumption and to drive abstinence-induced volume recovery. During the initial 2 weeks of abstinence no subcortical volume regain was observed. Either the time span was too short or the lower subcortical volume could represent a predisposing trait marker.

(c) 2015 S. Karger AG, Basel
\end{abstract}

(c) 2015 S. Karger AG, Base

$1022-6877 / 15 / 0222-0080 \$ 39.50 / 0$

\section{Introduction}

It is well recognized that excessive alcohol consumption causes widespread structural changes in the brain, and hence leads to related functional deficits. Plenty of studies have consistently reported loss of gray matter (GM) and white matter (WM) and increased cerebrospinal fluid in alcohol-dependent individuals (for review see $[1,2]$ ). For example, alcohol-dependent individuals showed volume shrinkage in reward network brain regions, and volume change of those structures was associated with post-treatment alcohol consumption [3]. Animal and human studies [4-6] have indicated that chronic alcohol abuse impairs the hippocampus, which elicits deficits in visuospatial learning and memory. One study [7] suggested that smaller amygdala volume in chronic alcoholics was associated with greater alcohol craving and relapse.

Notably, abstinent alcohol-dependent individuals show a partial regeneration of brain volume changes, even during early abstinence [8-10]. Brain volume regeneration appears to be greater during the first several weeks compared to continued long-term abstinence $[10,11]$. Moreover, a previous study [11] reported that alcoholics with pronounced brain volume loss at baseline experienced greater recovery during abstinence.

\section{KARGER 125}

E-Mail karger@karger.com

www.karger.com/ear
Guo-Ying Wang

Department of Neuroimaging, Central Institute of Mental Health

Medical Faculty Mannheim/Heidelberg University

DE-68159 Mannheim (Germany)

E-Mail guoying.wang@zi-mannheim.de 
However, most cross-sectional and longitudinal brain volume studies obtained baseline measurements several weeks after cessation of drinking [7, 12-15]. Obviously, those studies may miss the early short-term recovery effect and may underestimate the extent of brain impairment and the potential magnitude of recovery. Thus, in our previous study [8], voxel-based morphometry (VBM) was used to highlight the widespread volumetric changes due to excessive alcohol consumption and partial volume reversibility within the first 2 weeks of alcohol abstinence. Volume recovery was found only in cortical areas with different recovery extents. No difference in any subcortical areas including pallidum, amygdala, as well as hippocampus was detected, especially not in the reward system including caudate, putamen and nucleus accumbens, although these changes had been reported in other crosssectional and long-term abstinence studies in alcoholism $[3,16]$.

Subcortical volume differences could be easily overlooked. One study [17] reported that disease-induced hippocampal changes could not be detected by standard VBM analysis. However, several studies pointed out that Freesurfer is a robust tool to analyze the subcortical structures $[18,19]$, with comparable accuracy to the manual labeling approach [20]. In contrast to the subcortical segmentation procedure in VBM, the technique applied by Freesurfer directly assigns a neuroanatomical label to each voxel based on probabilistic information derived from a manually labelled training set. Additionally, the classification technique in Freesurfer also employs a registration procedure to robustly distinguish the within-structure variability in the intrinsic tissue parameters to get a more accurate segmentation [20].

In addition, VBM is not able to analyze cortical thickness (CTh). It is well documented that cortical volume includes 2 distinct properties: surface area (SA) and CTh, which have different cellular and genetic bases and are affected by different lifespan factors $[21,22]$. SA is associated with the number of radial columns, and appears to be influenced by various developmental factors, whereas $\mathrm{CTh}$ is related to the number of cells in a column, being highly vulnerable to environmental factors over the lifespan [23]. Furthermore, cortical GM volume variation across healthy subjects is mostly driven by differences in the cortical SA rather than in CTh $[21,24]$. Thus, it is important to study the morphometric properties of cortical GM volume, CTh, and SA independently.

Moreover, structural differences exist between the sulci and gyri across the cortical brain areas, with gyri having a greater number of neurons in deep layers [25], as well as different cell and dendrite morphology. A recent diffusion MRI study [26] pointed out that axonal connections are more concentrated in gyri relative to sulci. Another diffusion tensor imaging study [27] indicated that gyri are global functional connection centers and sulci are local functional hubs. Therefore, the sulci and gyri could be differentially affected by excessive alcohol consumption, and the initial recovery in early stage of abstinence could also differ. However, as far as our knowledge goes, no study has reported and addressed this issue yet.

We used Freesurfer (http://surfer.nmr.mgh.harvard. $\mathrm{edu} /$ ) to analyze our data, focusing on the volumetric changes in certain regions of interest (ROIs) in subcortical areas, CTh (sulcal and gyral pattern) and SA changes in cortical areas, associated with excessive alcohol consumption and early abstinence. Subcortical ROIs include caudate, putamen, pallidum, nucleus accumbens, amygdala, as well as hippocampus.

In summary, the main aims of our present study are (1) to test (with Freesurfer) which parts of the subcortical regions are affected by excessive alcohol consumption and undergo significant recovery within the first 2 weeks of abstinence in alcohol-dependent patients (ADPs); (2) to gain a deeper insight into the underlying mechanisms that contribute to dynamic cortical volumetric changes in ADPs within the first 2 weeks of abstinence [8] by examining the CTh and SA; (3) to test whether and how the pattern of gyri and sulci are differentially affected by excessive alcohol consumption, and whether the extents of recovery are different.

\section{Materials and Methods}

\section{Participants}

Forty-nine ADPs and 20 healthy controls (HCs) were included in our study. Group demographic data are summarized in table 1. Treatment-seeking alcoholic inpatients were recruited from the Department of Addiction Medicine at the Central Institute of Mental Health in Mannheim, Germany. Patients met the DSM-IV and ICD10 criteria for alcohol dependence at the time of enrollment. They were first scanned within 1 day after their last alcoholic drink (TP1), and re-scanned after 14 days of abstinence (TP2). The severity of alcohol dependence was assessed with the Alcohol Dependence Scale [28]. Alcohol craving and drinking behavior were evaluated by the German version of the Obsessive Compulsive Drinking Scale [29] (table 1). The age-matched HC group, who underwent $2 \mathrm{MRI}$ measurements in a 14 days interval, was recruited by newspaper advertisement.

Exclusion criteria for all participants were dependence on any substance other than alcohol or nicotine, any psychotropic med- 


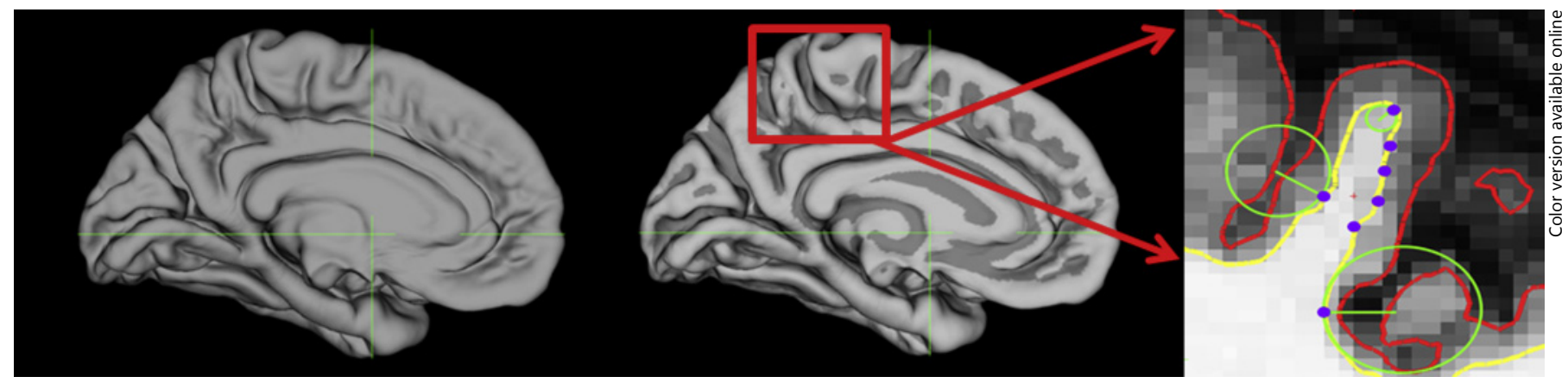

Fig. 1. The brain surface in the middle aspect of the brain cortex (left). The same image after calculating and color-labelling the convexity and curvature of the sulci (dark gray) and gyri (light gray) (middle). An example of how to differentiate gyri and sulci

Table 1. Demographic data for alcohol-dependent patients and healthy controls

\begin{tabular}{|c|c|c|c|c|}
\hline & \multicolumn{2}{|c|}{$\begin{array}{l}\text { Alcohol } \\
\text { dependent } \\
\text { patients }\end{array}$} & \multicolumn{2}{|c|}{ Health controls } \\
\hline & mean & SD & mean & SD \\
\hline Total number & 49 & - & 20 & - \\
\hline Number of female & 9 & - & 3 & - \\
\hline Number of male & 40 & - & 17 & - \\
\hline Age, years & 47.02 & 10.00 & 46.65 & 12.37 \\
\hline Alcohol, g, per drinking day* & 211.05 & 147.35 & 22.11 & 10.48 \\
\hline Alcohol dependence scale* & 15.11 & 7.70 & 0.47 & 1.87 \\
\hline $\begin{array}{l}\text { Obsessive compulsive } \\
\text { drinking scale* }\end{array}$ & 21.45 & 9.36 & 2.60 & 2.80 \\
\hline
\end{tabular}

* Significantly different between 2 groups $(\mathrm{p}<0.001)$.

ication in the past 3 months, positive urine drug tests, brain injury history, other neurological or severe physiological illness (e.g. severe diabetes, HIV), hepatic encephalopathy, liver cirrhosis, and MRI-related exclusion criteria (e.g. metal implants, pace makers).

All participants provided written informed consent prior to the study. The study was approved by the ethics committee of the medical faculty Mannheim of Heidelberg University. Detailed information on the participants' medication has been provided in our earlier work [8].

\section{MRI Image Acquisition}

MRI measurements were conducted at a Siemens Tim Trio 3T scanner (Erlangen, Germany) using a 12-channel head coil. A high-resolution 3D T1-weighted (MPRAGE) data set was acquired for each participant. Imaging parameters were as follows: repetition time $\mathrm{TR}=2,300 \mathrm{~ms}$; echo time $\mathrm{TE}=3.03 \mathrm{~ms}$; inversion time $\mathrm{TI}=900 \mathrm{~ms}$; flip angle $9^{\circ} ; 192$ slices; field of view $256 \times 256 \mathrm{~mm}^{2}$; voxel size $1 \times 1 \times 1 \mathrm{~mm}^{3}$. based on the curvature value (right). Curvature $=1$ /radius of circle (circle tangent to surface at each vertex). Vertices with a positive mean curvature value were served as sulci, and vertices with nonpositive values were served as gyri.

\section{MRI Image Analysis}

Before preprocessing with Freesurfer, the data sets were inspected for the homogeneity and quality control via VBM8 (http://www.neuro.uni-jena.de/vbm/). Volume, CTh, SA and subcortical volume were processed with the Freesurfer 5.1.0 software package. In brief, the processing stream includes motion correction, removal of non-brain tissue [30], automated Talairach transformation, segmentation of the cortical GM and WM volumes and deep GM volumetric structures [31], intensity normalization [32], tessellation of the GM/WM boundary, automated topology correction [33], as well as surface deformation to define the grey/white and pial surface $[34,35]$. For each subject, CTh was calculated as the shortest distance from the GM/WM boundary to the GM/cerebrospinal fluid boundary at each vertex on the tessellated surface [35]. SA was calculated by summing up the area of the vertices in each parcellation. Subcortical volume was calculated by voxel counting, based on an atlas containing probabilistic information for the structure classifications [20]. Additionally, for the analysis of the longitudinal changes, an unbiased within-subject template space and average image was created using robust, inverse consistent registration [36]. The post-possessing outputs were visually inspected and manually edited (if necessary) to assure the processing accuracy. To enable inter-subject and intra-subject comparison, the data for each subject was normalized to a standard surface template in a spherical surface-based coordinate system provided by Freesurfer - to allow for a much higher localization accuracy of structural features of the brain across participants - and concatenated into a single image. Finally, this image was smoothed with a $10 \mathrm{~mm}$ full width at half maximum Gaussian kernel to improve the signal-to-noise ratio and reduce local variations [37] in the measurements for further analysis. The quantitative estimates were driven in a set of spatially distinct ROI obtained using the sulcogyral-based atlas (68 ROI parcellations) [38], and for further and more detailed investigations of gyri and sulci, an atlas with $148 \mathrm{ROI}$ parcellations was used [39]. Figure 1 illustrates the visualization of the cortical surface, and its division into sulci and gyri.

\section{Statistical Analysis}

Statistical analysis was performed using Freesurfer's Qdec (version 1.4) and SPSS software version 21 (IBM, Chicago, Ill., USA). All demographic and neuroanatomical measures were tested for 
normal distribution using the Kolmogorov-Smirnov and Shapiro-Wilk tests. Group differences of demographic measures (before scan 1) were assessed by independent two sample t tests, with $\mathrm{p}$ threshold set at 0.05 .

In the previous VBM analysis [8], we tested whether there was a significant difference in GM volume between the smoking and non-smoking subgroup of ADP. We found no smoking effects on GM volume in our patients' sample. Thus, based on the prior analysis, we did not include the smoking behavior as a covariate in the current paper.

To avoid possible bias due to different brain volumes across subjects, the estimated total intracranial volume (eTIV) was calculated as the volume enclosed by the pial surface. In addition, to control for possible cortical folding features impacting on CTh results, a general linear model analysis was performed on cortical folding characteristics, such as the depth of sulci of each vertex (SULC), the curvature of cortical surface (CURV), as well as the amount of convolution and displacement needed to warp the cortical surface during the registration (JACOBIAN_WHITE). These three parameters (SULC, CURV, and JACOBIAN_WHITE) were automatically calculated by Freesurfer.

We first analyzed the global measures (total GM volume, total cortical volume, total subcortical volume, total WM volume, total SA and mean total CTh) to get an impression of alcohol abuse and abstinence-related effects on brain morphological alterations. Then, to corroborate these findings, local morphological measures (local CTh, local SA and ROI subcortical volume) were assessed. Furthermore, we did a separate analysis of gyral and sulcal CTh in these significant local ROIs to further investigate the underlying mechanisms. Age and gender were set as covariates for all analyses. Since the eTIV was found to be related only to the SA but not to the CTh both in our analysis and other studies (https://surfer.nmr. mgh.harvard.edu/fswiki/eTIV), the eTIV was used only as a covariate when we computed the volume and SA measures.

Cross-Sectional Analysis

A general linear model with age and gender as covariates (and eTIV for volume and SA measures) was used to test group differences at each time point (TP) in global and regional/local measures between HCs and ADPs. Briefly, global measures and ROI subcortical volumes were assessed by multivariate analysis with covariates (MANCOVA) with the threshold set at $\mathrm{p}<0.05$ with Bonferroni correction. Statistical parametric maps of the local CTh and local SA were assessed at each surface vertex of the entire cortical mantle. Results were corrected for multiple comparisons with false discovery rate at $\mathrm{p}<0.05$.

\section{Longitudinal Analysis}

Mixed factorial ANCOVAs followed by paired $t$ tests were used for longitudinal analysis between patients and controls when global measures and ROI subcortical volumes were calculated. Covariates were also age and gender (and eTIV for volume and SA measures). The main effect for diagnosis, time, and the interaction of diagnosis-by-time were tested. The significant threshold was set at $p<0.05$ with Bonferroni correction. The extent of longitudinal changes in CTh and SA was defined as (measure at TP2-measure at $\mathrm{TP} 1 /$ measure at $\mathrm{TP} 1)^{*} 100$, since all participants were scanned with the same interval (14 days) between both measurements. For comparisons of the local CTh and local SA, cluster-wise correction for multiple comparisons was performed with Monte Carlo simu- lations (vertex-wise threshold $\mathrm{p}<0.05,5,000$ iterations). Clusterwise probabilities are reported, which represent the likelihood of finding a maximum cluster size during simulations [40].

\section{Results}

\section{Participants' Characterization}

Characteristics of participants for the 2 groups are shown in table 1 . No significant differences were noted in gender composition and age between the 2 groups. In comparison to controls, ADPs rated significantly higher on the Alcohol Dependence Scale as well as the Obsessive Compulsive Drinking Scale (both $\mathrm{p}<0.001$ ).

\section{Volume, SA, and CTh}

\section{Global Measures}

MANCOVA results revealed group differences in global measures between HCs and ADPs at both measurement TPs. Specifically, compared to HCs, ADPs exhibited lower global measures in total GM volume $(\mathrm{TP} 1: \mathrm{F}(1,64)=28.562, \mathrm{p}<0.001 ; \mathrm{TP} 2: \mathrm{F}(1,64)=$ $28.170, \mathrm{p}<0.001)$, total cortical volume $(\mathrm{TP} 1: \mathrm{F}(1,64)=$ 24.187, $\mathrm{p}<0.001$; TP2: $\mathrm{F}(1,64)=23.800, \mathrm{p}<0.001)$, total subcortical volume (TP1: $\mathrm{F}(1,64)=23.516, \mathrm{p}<$ 0.001; TP2: $\mathrm{F}(1,64)=21.312, \mathrm{p}<0.001)$, mean total CTh $(\mathrm{TP} 1: \mathrm{F}(1,64)=34.362, \mathrm{p}<0.001 ; \mathrm{TP} 2: \mathrm{F}(1,64)=$ $28.562, \mathrm{p}<0.001)$. No difference was found in the global WM volume and total SA between HCs and ADPs for both TPs ( $\mathrm{p}>0.05)$.

Longitudinally, a $2 \times 2$ mixed factorial MANCOVA was conducted with the diagnosis as between-subjects factor and the time as a within-subjects factor. Significant diagnosis-by-time interaction effect was found for the mean total CTh $(F(1,65)=7.996, p=0.036)$. No interaction was seen in total GM volume, total WM volume, total cortical volume, total subcortical volume, and total SA (all $\mathrm{p}>0.05)$. Further, follow-up paired t tests revealed no between-scan changes in any global measures in HCs, while ADPs demonstrated longitudinal increases in global measures of mean total CTh $(\mathrm{p}<0.001)$.

\section{Regional Subcortical Volumes}

Smaller volumes in ADPs compared to HCs were evident for both TPs and located bilaterally in the putamen (TP1: left $\mathrm{p}=0.012$, right $\mathrm{p}=0.012 ; \mathrm{TP} 2$ : left $\mathrm{p}=0.012$, right $\mathrm{p}=0.012$ ), nucleus accumbens (TP1: left $\mathrm{p}<0.001$, right $\mathrm{p}=0.012$; TP2: left $\mathrm{p}=0.012$, right $\mathrm{p}=0.024)$, amygdala (TP1: left $\mathrm{p}<0.001$, right $\mathrm{p}<0.001$; TP2: left $\mathrm{p}<$ 0.001 , right $\mathrm{p}<0.001$ ) as well as hippocampus (TP1: left 


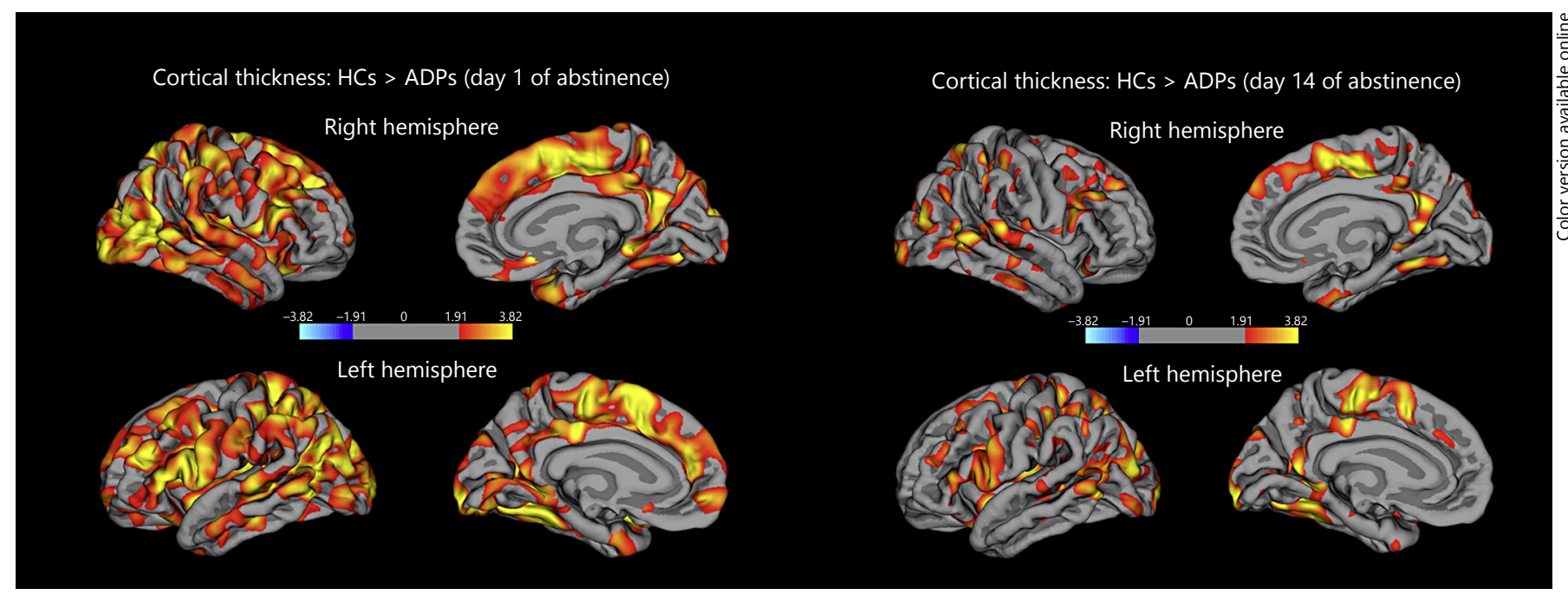

Fig. 2. Areas of CTh loss in ADPs at day 1 (left) and day 14 (right) of abstinence compared to HCs; $\mathrm{p}<0.05$, false discovery rate corrected). The value of the scale bar represents $-\log _{10}(\mathrm{p})=1.3$, with $\mathrm{p}=0.05$.

$\mathrm{p}=0.012$, right $\mathrm{p}<0.001 ;$ TP2: left $\mathrm{p}=0.012$, right $\mathrm{p}=$ $0.012)$. No group differences in the bilateral caudate and pallidum volumes were observed both at the TP1 and TP2 $(\mathrm{p}>0.05)$.

Longitudinally, the $2 \times 2$ mixed factorial MANCOVA revealed that no significant diagnosis-time interaction was found for any of the 12 subcortical ROIs (bilateral caudate, putamen, pallidum, nucleus accumbens, amygdala, and hippocampus; $\mathrm{p}>0.05$ ).

\section{Local CTh}

Figure 2 illustrates areas of cortical thinning in ADPs relative to HCs at TP1 and TP2, respectively. On day 1 of abstinence (TP1), compared to HCs, ADPs demonstrated widespread lower CTh across the whole brain cortex. Differences between the ADPs and HCs were significant bilaterally in the medial orbitofrontal area, superior, middle and inferior part of frontal lobe, fusiform (extending to inferior temporal, lateral occipital lobe), inferior parietal (extending to postcentral, superior parietal lobe), in the left entorhinal and left lateral orbitofrontal area, as well as in the right rostral anterior cingulate (rostral ACC). After 14 days of abstinence (TP2), a partial recovery of cortical thinning was observed, but most of the regions remained significantly different between groups, including bilateral superior parietal, superior frontal, precentral, superior and inferior temporal areas. However, group differences of CTh for the bilateral medial orbitofrontal area and right rostral ACC could not be detected anymore.

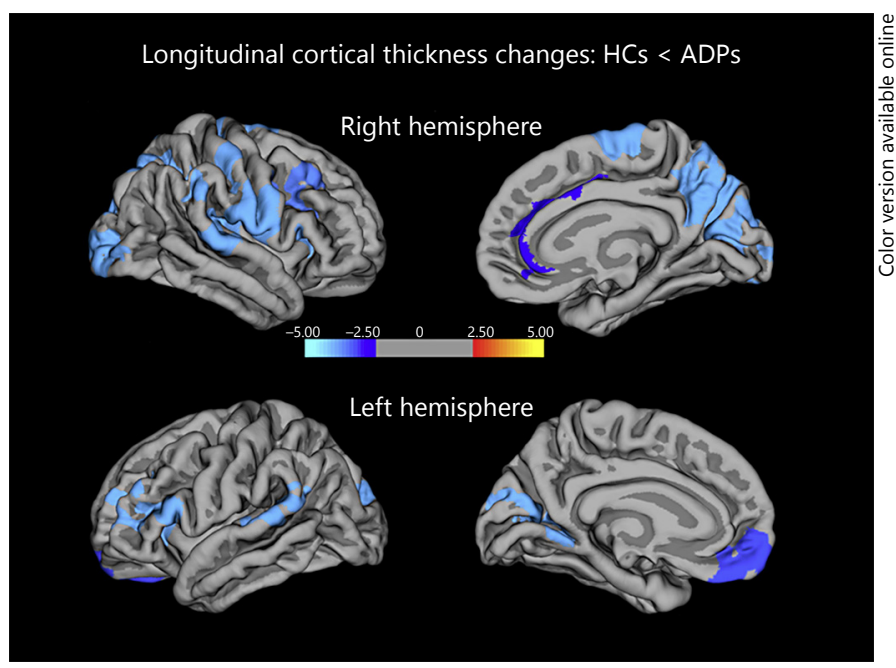

Fig. 3. Areas of CTh regaining in ADPs vs. HCs after the first 14 days of abstinence (Monte Carlo simulation: vertex-wise threshold $\mathrm{p}<0.05,5,000$ iterations). The value of the scale bar represents $\log _{10}(\mathrm{p})=1.3$, with $\mathrm{p}=0.05$.

Longitudinally, the comparison of changes in CTh over the first 2 weeks of abstinence (TP2 - TP1) between ADPs and HCs demonstrated an increase of CTh in the ADP group in the bilateral lateral occipital, bilateral precentral, right postcentral, right cuneus, right caudal middle frontal, right superior frontal, right rostral ACC, left medial orbitofrontal, left parsopercularis, left lingual and left inferior parietal area (fig. 3; table 2). No longitudinal CTh changes were observed in HCs in this time period. 
Table 2. Peak voxel of regions with CTh regain in alcohol-dependent patients vs. healthy controls within the first 2 weeks of abstinence

\begin{tabular}{|c|c|c|c|c|c|c|c|}
\hline Hemisphere & Significant clusters & $\operatorname{Max}$ & Size $\left(\mathrm{mm}^{2}\right)$ & TalX & TalY & TalZ & CWP \\
\hline \multirow[t]{5}{*}{ Left } & Lateral occipital & -4.561 & 613.72 & -23.7 & -87.2 & -6.2 & 0.0392 \\
\hline & Medial orbitofrontal & -4.097 & $1,034.17$ & -6 & 56.5 & -11.9 & 0.001 \\
\hline & Lingual & -3.127 & $1,767.49$ & -12.9 & -55 & 1.6 & 0.0001 \\
\hline & Precentral & -2.969 & 715.03 & -41.9 & -5.1 & 44.8 & 0.015 \\
\hline & Inferior parietal & -2.875 & $1,197.98$ & -43 & -50.8 & 22.4 & 0.0001 \\
\hline \multirow{6}{*}{ Right } & Cuneus & -4.09 & $4,918.99$ & 10.7 & -66 & 19.4 & 0.0001 \\
\hline & Lateral occipital & -3.455 & $1,644.23$ & 24.8 & -81.5 & -4 & 0.0001 \\
\hline & Caudal-middle frontal & -3.361 & 681.71 & 33.9 & 1.3 & 41.8 & 0.046 \\
\hline & Precentral & -3.121 & $1,337.34$ & 40.9 & 5.2 & 21.2 & 0.0003 \\
\hline & Superior frontal & -2.971 & $2,067.37$ & 12.1 & 3.5 & 61 & 0.0001 \\
\hline & Rostral anterior cingulate & -2.39 & 930.46 & 6.8 & 37 & -2.6 & 0.0059 \\
\hline
\end{tabular}

Age and gender were set as covariates; Monte Carlo simulations were used for cluster-wise correction: vertex-wise threshold $\mathrm{p}<0.05$, 5,000 iterations. CWP $=$ Cluster-wise $\mathrm{p}$ value.

Table 3. Gyral and sulcal CTh for affected regions

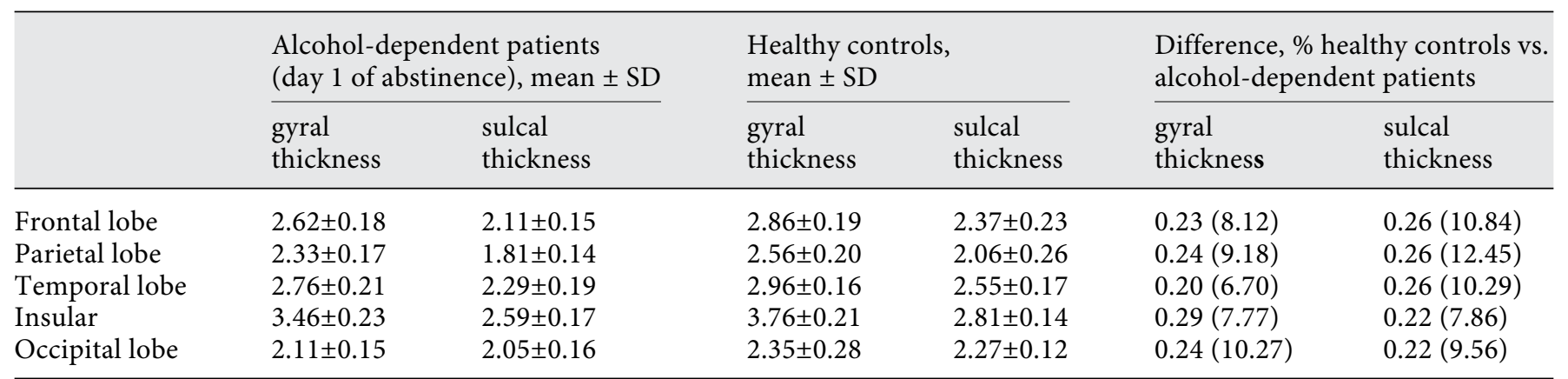

Difference represents absolute differences value of cortical thickness in mm between the 2 groups; \% represents the difference in percentage relative to the cortical thickness in healthy controls.

Gyral and Sulcal CTh of the Affected Regions in

ADPs

For the sake of clarity, the data of gyral and sulcal CTh were calculated and presented as average bilateral CTh in each lobe. Separate analysis of gyral and sulcal parts of the significant affected brain regions are shown in figure 2 (day 1 of abstinence) suggested that each of those regions was thicker in gyri compared to sulci (all $p<0.01$ ). On a descriptive level, CTh differences between ADPs and $\mathrm{HCs}$ were more pronounced in sulcal relative to gyral parts in frontal lobe, parietal lobe, insular as well as temporal lobe (table 3 ). The regeneration extents of sulci in all affected regions were more pronounced in sulci than in gyri during the first 14 days of abstinence. The paired $t$ test showed that the recovery magnitude of the frontal sulci was significantly greater than that of gyri $(\mathrm{p}=0.01$; table 4).

\section{Local SA}

In local SA, no significant group differences between HCs and ADPs, as well as no significant longitudinal changes within the first 2 weeks of abstinence could be detected.

\section{Cortical Folding Parameters}

There were no between-group (ADPs vs. HCs) and longitudinal changes (TP2 - TP1) in cortical folding parameters for SULC, CURV, and JACOBIAN_WHITE, indicating that folding parameters have no effect on CTh. 
Table 4. Abstinence-induced regain of gyral and sulcal CTh for affected regions

\begin{tabular}{llll}
\hline Regions & $\begin{array}{l}\text { Changes in gyri, } \\
\text { mean (\%) }\end{array}$ & $\begin{array}{l}\text { Changes in sulci, } \\
\text { mean (\%) }\end{array}$ & p value \\
\hline Frontal & $0.0009(0.028)$ & $0.0313(1.69)$ & 0.01 \\
Insular & $0.0148(0.50)$ & $0.0375(1.58)$ & 0.27 \\
Parietal & $0.0283(1.25)$ & $0.0265(1.56)$ & 0.78 \\
Occipital & $0.0187(0.94)$ & $0.0329(1.82)$ & 0.36 \\
Temporal & $0.0295(1.12)$ & $0.0421(1.97)$ & 0.26 \\
\hline
\end{tabular}

Mean represents the mean value of absolute cortical thickness increase in $\mathrm{mm}$; \% represents the regeneration percentage relative to the baseline cortical thickness.

\section{Discussion}

Our study aimed at investigating the subcortical volumes affected by chronic alcohol dependence and initial regain within the first 2 weeks of abstinence in ADPs. Moreover, this is also the first report to explore the nature of the partial recovery for the brain volume loss during the first 2 weeks of alcohol abstinence, as well as the gyral and sulcal pattern of affected CTh reduction and abstinence-induced recovery. The novel findings were as follows: (1) ADPs at day 1 of abstinence demonstrated significantly lower subcortical volumes than HCs in most reward system regions, including putamen, nucleus accumbens, amygdala, hippocampus. However, no area showed significant subcortical volume regain within the first 14 days of abstinence in ADPs. (2) In ADPs, the cortical volume recovery during the first 2 weeks of abstinence is predominantly driven by an increase in CTh. No significant longitudinal change in SA was seen either on a global or local level. (3) The CTh reduction is more pronounced in sulci than gyri across the affected regions. Greater sulcal than gyral CTh recovery in affected areas were seen during the first 2 weeks of sobriety.

The impairment of subcortical structures has been consistently reported in alcohol-dependent individuals, especially the reward circuit is associated with chronic alcohol dependence and relapse [3, 41-44]. Our study, replicating previous findings, found that ADPs at day 1 of abstinence have smaller volumes of reward-related structures (including amygdala, putamen, nucleus accumbens, hippocampus), and these statistically significant differences still persist after 2 weeks of alcohol abstinence. This is in good concordance with lower volumes of the reward system in alcohol abstainers with maintained sobriety for 12 months $[14,44]$. There are also results by a cross-sec- tional study that reveal only minimal differences in subcortical volumes between alcoholics with about 6 years of sustained abstinence and nonalcoholic controls [16]. Moreover, consistent with our previous observation [8], no significant volumetric recovery of the subcortical structures was observed in current study, even with different approaches to analyze it. Remaining subcortical volume reductions despite long-term abstinence either suggests a non-reversible alcohol-induced damage of subcortical structures, or as just recently discovered a genetically determined smaller volume of subcortical structures [45]. Thus it should be considered that subjects developing alcohol dependence could have genetically determined smaller subcortical volumes potentially predisposing for alcoholism. Hence, longitudinal studies with a first measurement of subcortical volumes before starting alcohol use, further measurements after the development of alcoholism and long-term abstinence would be necessary to clarify this issue.

To further describe the nature of abstinence-induced volume changes, we examined both SA and CTh in this study. Our results suggest that no longitudinal changes occurred in any global and local SA during the first 2 weeks of abstinence, but region-specific increase in CTh is the main feature. Specifically, there were pronounced increases in CTh in the medial orbitofrontal, middle frontal, superior frontal, rostral ACC, precentral, postcentral, cuneus, inferior parietal and lateral occipital regions in ADPs within the first 2 weeks of abstinence.

The possible mechanisms behind the structural recovery are rehydration effect, axonal and dendritic regrowth, remyelinations, glial cell alterations, cerebral perfusion increase via improving microvasculature function or metabolite increase [12, 46-50]. These factors may differentially contribute to structural recovery at different TPs during abstinence. Increased myo-inositol (an index for glial cell activation) in ACC was found only in recently detoxified but not long-term abstinent alcoholics [49]. However, the mechanism underlying the recovery of CTh during the first 2 weeks of abstinence is still unclear.

It is interesting to note that only after 14 days of abstinence, the CTh differences in the bilateral middle orbitofrontal cortex and right rostral ACC between HC and ADPs cannot be observed anymore. This might be a hint that the frontal lobe appears to be a very susceptible region to recover over the first 2 weeks of abstinence. Early pathology work also indicates that alcohol preferentially effects on pyramidal neurons in the frontal cortex. Alcohol-related changes in neocortical neuronal loss and dendritic shrinkage may lead to cortical thinning, but the 
dendrite shrinkage could be fast reversible by alcohol abstinence [47].

Last, we extend our observations to the gyral and sulcal pattern of CTh loss and abstinence-induced partial recovery. Our results indicate that ADPs have more prominent shrinkage in sulcal than gyral parts of affected regions, suggesting that the atrophy effect of excessive alcohol consumption differs between gyri and sulci. Additionally, after 14 days of abstinence, ADPs demonstrated a greater thickness recovery in the sulcal part of affected areas than the gyral part, particularly evident in frontal regions. Taken together, those results indicate that sulci are more susceptive to excessive alcohol consumption, and abstinence-induced recovery. In the future, a longitudinal animal model study is needed to explore the mechanisms behind this sulci-gyri differential vulnerability effect to alcohol.

In fact, there are distinct lines of evidence in support of our observation of a differential effect for sulci compared to gyri. A previous study indicated that the cytoarchitecture of gyri and sulci is greatly different in the human brain [51]. Additionally, a significant difference between gyri and sulci in the axonal connectivity function and gene expression was found both in animals and humans $[27,52]$. A multimodal diffusion tensor imaging/ fMRI study [27] suggested that gyri are more related to longer connections that exchange information among distant structurally connected cortical regions via dense fibers, while sulci are more related to shorter connections that communicate directly with their neighboring gyri and indirectly exchange information with remote regions through gyri. Based on those indications, our data suggest that short distance connections are more susceptive for excessive alcohol consumption and abstinence. Actually, functional connectivity alterations in alcoholism have repeatedly been reported [53-55].

In conclusion, in this study we suggest that CTh alteration could be the mechanism corresponding to the previously observed partial volumetric recovery [8] dur- ing the first 2 weeks of abstinence in ADPs. The observation that the differences observed in the frontal lobe between patients and controls on day 1 of abstinence were not evident any more on day 14 might hint that the frontal lobe is a very susceptible region to abstinence-related recovery. Moreover, this is also the first report to reveal that alcohol differentially impacts sulci and gyri of the neocortex. Sulci are more susceptive to excessive alcohol consumption and abstinence-induced recovery. In light of current theories of the functional model of gyri and sulci, these changes may reflect aberrations in cerebral and subcortical connectivity. In addition, in contrast to multiple regional cortical GM regeneration within 14 days of abstinence, no subcortical volumetric recovery in the reward system was found, suggesting that the subcortical structures are damaged irreversible by alcohol or that genetically determined smaller volume of subcortical structures mediates susceptibility for alcoholism. These sustained subcortical GM alterations may attribute to the self-sustaining alcohol seeking behavior, cognitive and behavioral deficits in ADPs.

\section{Limitations}

For the statistics, mixed factorial MANCOVA was used only for global measures and regional subcortical volume analysis. Since the linear mixed effect analysis is not available for the FS5.1 version, local CTh was estimated by the longitudinal percentage CTh change. In addition, head motion could also affect the CTh measurement [56]. The homogeneity and quality of the data sets were inspected via VBM8. However, it would be more accurate to account for the motion effect if we could estimate the motion levels and use them as a covariate.

\section{Acknowledgments}

This work was supported by the Deutsche Forschungsgemeinschaft (SFB636, project D7 to G.E. and K.M.).

\section{References}

1 Bühler M, Mann K: Alcohol and the human brain: a systematic review of different neuroimaging methods. Alcohol Clin Exp Res 2011; 35:1771-1793.

2 Krienke UJ, Nikesch F, Spiegelhalder K, Hennig J, Olbrich HM, Langosch JM: Impact of alcohol-related video sequences on functional MRI in abstinent alcoholics. Eur Addict Res 2014;20:33-40.
3 Makris N, Oscar-Berman M, Jaffin SK, Hodge SM, Kennedy DN, Caviness VS, Marinkovic K, Breiter HC, Gasic GP, Harris GJ: Decreased volume of the brain reward system in alcoholism. Biol Psychiatry 2008;64:192-202. 4 Matthews DB, Morrow AL: Effects of acute and chronic ethanol exposure on spatial cognitive processing and hippocampal function in the rat. Hippocampus 2000;10:122-130.
5 White AM, Matthews DB, Best PJ: Ethanol memory, and hippocampal function: a review of recent findings. Hippocampus 2000;10:8893.

6 Silvers JM, Tokunaga S, Berry RB, White AM, Matthews DB: Impairments in spatial learning and memory: ethanol, allopregnanolone, and the hippocampus. Brain Res Brain Res Rev 2003;43:275-284. 
7 Wrase J, Makris N, Braus DF, Mann K, Smolka MN, Kennedy DN, Caviness VS, Hodge SM, Tang L, Albaugh M, Ziegler DA, Davis OC, Kissling C, Schumann G, Breiter HC, Heinz A: Amygdala volume associated with alcohol abuse relapse and craving. Am J Psychiatry 2008;165:1179-1184.

8 van Eijk J, Demirakca T, Frischknecht U, Hermann D, Mann K, Ende G: Rapid partial regeneration of brain volume during the first 14 days of abstinence from alcohol. Alcohol Clin Exp Res 2013;37:67-74.

9 Demirakca T, Ende G, Kämmerer N, WelzelMarquez H, Hermann D, Heinz A, Mann K: Effects of alcoholism and continued abstinence on brain volumes in both genders. Alcohol Clin Exp Res 2011;35:1678-1685.

10 Pfefferbaum A, Sullivan EV, Mathalon DH, Shear PK, Rosenbloom MJ, Lim KO: Longitudinal changes in magnetic resonance imaging brain volumes in abstinent and relapsed alcoholics. Alcohol Clin Exp Res 1995;19:11771191.

11 Gazdzinski S, Durazzo TC, Meyerhoff DJ: Temporal dynamics and determinants of whole brain tissue volume changes during recovery from alcohol dependence. Drug Alcohol Depend 2005;78:263-273.

12 Durazzo TC, Gazdzinski S, Mon A, Meyerhoff DJ: Cortical perfusion in alcohol-dependent individuals during short-term abstinence: relationships to resumption of hazardous drinking after treatment. Alcohol 2010; 44:201-210.

13 Fein G, Landman B, Tran H, McGillivray S, Finn P, Barakos J, Moon K: Brain atrophy in long-term abstinent alcoholics who demonstrate impairment on a simulated gambling task. Neuroimage 2006;32:1465-1471.

14 Sullivan EV, Deshmukh A, De Rosa E, Rosenbloom MJ, Pfefferbaum A: Striatal and forebrain nuclei volumes: contribution to motor function and working memory deficits in alcoholism. Biol Psychiatry 2005;57:768-776.

15 Shear PK, Jernigan TL, Butters N: Volumetric magnetic resonance imaging quantification of longitudinal brain changes in abstinent alcoholics. Alcohol Clin Exp Res 1994;18:172-176.

16 Sameti M, Smith S, Patenaude B, Fein G: Subcortical volumes in long-term abstinent alcoholics: associations with psychiatric comorbidity. Alcohol Clin Exp Res 2011;35:10671080.

17 Bergouignan L, Chupin M, Czechowska Y, Kinkingnéhun S, Lemogne C, Le Bastard G, Lepage M, Garnero L, Colliot O, Fossati P: Can voxel based morphometry, manual segmentation and automated segmentation equally detect hippocampal volume differences in acute depression? Neuroimage 2009; 45:29-37.

18 Tae WS, Kim SS, Lee KU, Nam EC, Kim KW: Validation of hippocampal volumes measured using a manual method and two automated methods (freesurfer and ibaspm) in chronic major depressive disorder. Neuroradiology 2008;50:569-581.
19 Dewey J, Hana G, Russell T, Price J, McCaffrey D, Harezlak J, Sem E, Anyanwu JC, Guttmann CR, Navia B, Cohen R, Tate DF: Reliability and validity of MRI-based automated volumetry software relative to auto-assisted manual measurement of subcortical structures in HIV-infected patients from a multisite study. Neuroimage 2010;51:1334-1344.

20 Fischl B, Salat DH, Busa E, Albert M, Dieterich $M$, Haselgrove $C$, van der Kouwe A, Killiany R, Kennedy D, Klaveness S, Montillo A, Makris N, Rosen B, Dale AM: Whole brain segmentation: automated labeling of neuroanatomical structures in the human brain. Neuron 2002;33:341-355.

21 Winkler AM, Kochunov P, Blangero J, Almasy L, Zilles K, Fox PT, Duggirala R, Glahn DC: Cortical thickness or grey matter volume? The importance of selecting the phenotype for imaging genetics studies. Neuroimage 2010;53:1135-1146.

22 Hogstrom LJ, Westlye LT, Walhovd KB, Fjell AM: The structure of the cerebral cortex across adult life: age-related patterns of surface area, thickness, and gyrification. Cereb Cortex 2013;23:2521-2530.

23 Momenan R, Steckler LE, Saad ZS, van Rafelghem S, Kerich MJ, Hommer DW: Effects of alcohol dependence on cortical thickness as determined by magnetic resonance imaging. Psychiatry Res 2012;204:101-111.

24 Im K, Lee JM, Yoon U, Shin YW, Hong SB, Kim IY, Kwon JS, Kim SI: Fractal dimension in human cortical surface: multiple regression analysis with cortical thickness, sulcal depth, and folding area. Hum Brain Mapp 2006;27: 994-1003.

25 Welker W: Why does cerebral cortex fissure and fold? Cereb Cortex 1990;8:3-136.

26 Nie J, Guo L, Li K, Wang Y, Chen G, Li L, Chen H, Deng F, Jiang X, Zhang T, Huang L, Faraco C, Zhang D, Guo C, Yap PT, Hu X, Li G, Lv J, Yuan Y, Zhu D, Han J, Sabatinelli D, Zhao Q, Miller LS, Xu B, Shen P, Platt S, Shen D, Hu X, Liu T: Axonal fiber terminations concentrate on gyri. Cereb Cortex 2012;22: 2831-2839.

27 Deng F, Jiang X, Zhu D, Zhang T, Li K, Guo L, Liu T: A functional model of cortical gyri and sulci. Brain Struct Funct 2014;219:14731491.

28 Skinner HA, Allen BA: Alcohol dependence syndrome: measurement and validation. J Abnorm Psychol 1982;91:199-209.

29 Mann K, Ackermann K: Die OCDS-G: psychometrische kennwerte der deutschen version der obsessive compulsive drinking scale. Sucht 2000;46:90-100.

30 Ségonne F, Dale AM, Busa E, Glessner M, Salat D, Hahn HK, Fischl B: A hybrid approach to the skull stripping problem in MRI. Neuroimage 2004;22:1060-1075.

31 Fischl B, Salat DH, van der Kouwe AJ, Makris $\mathrm{N}$, Ségonne F, Quinn BT, Dale AM: Sequenceindependent segmentation of magnetic resonance images. Neuroimage 2004;23(suppl 1):S69-S84
32 Sled JG, Zijdenbos AP, Evans AC: A nonparametric method for automatic correction of intensity nonuniformity in MRI data. IEEE Trans Med Imaging 1998;17:87-97.

33 Ségonne F, Pacheco J, Fischl B: Geometrically accurate topology-correction of cortical surfaces using nonseparating loops. IEEE Trans Med Imaging 2007;26:518-529.

34 Dale AM, Fischl B, Sereno MI: Cortical surface-based analysis. I. Segmentation and surface reconstruction. Neuroimage 1999;9:179194.

35 Fischl B, Dale AM: Measuring the thickness of the human cerebral cortex from magnetic resonance images. Proc Natl Acad Sci U S A 2000;97:11050-11055.

36 Reuter M, Schmansky NJ, Rosas HD, Fischl B: Within-subject template estimation for unbiased longitudinal image analysis. Neuroimage 2012;61:1402-1418.

37 Du AT, Schuff N, Kramer JH, Rosen HJ, Gorno-Tempini ML, Rankin K, Miller BL, Weiner MW: Different regional patterns of cortical thinning in Alzheimer's disease and frontotemporal dementia. Brain 2007;130(pt 4):1159-1166.

38 Desikan RS, Ségonne F, Fischl B, Quinn BT, Dickerson BC, Blacker D, Buckner RL, Dale AM, Maguire RP, Hyman BT, Albert MS, Killiany RJ: An automated labeling system for subdividing the human cerebral cortex on MRI scans into gyral based regions of interest. Neuroimage 2006;31:968-980.

39 Destrieux C, Fischl B, Dale A, Halgren E: Automatic parcellation of human cortical gyri and sulci using standard anatomical nomenclature. Neuroimage 2010;53:1-15.

40 Hagler DJ Jr, Saygin AP, Sereno MI: Smoothing and cluster thresholding for cortical surface-based group analysis of fMRI data. Neuroimage 2006;33:1093-1103.

41 Bauer J, Pedersen A, Scherbaum N, Bening J, Patschke J, Kugel H, Heindel W, Arolt V, Ohrmann P: Craving in alcohol-dependent patients after detoxification is related to glutamatergic dysfunction in the nucleus accumbens and the anterior cingulate cortex. Neuropsychopharmacology 2013;38:14011408.

42 Kuceyeski A, Meyerhoff DJ, Durazzo TC, Raj A: Loss in connectivity among regions of the brain reward system in alcohol dependence. Hum Brain Mapp 2013;34:3129-3142.

43 Segobin SH, Chételat G, Le Berre AP, Lannuzel C, Boudehent C, Vabret F, Eustache F, Beaunieux H, Pitel AL: Relationship between brain volumetric changes and interim drinking at six months in alcohol-dependent patients. Alcohol Clin Exp Res 2014;38:739748.

44 Durazzo TC, Tosun D, Buckley S, Gazdzinski S, Mon A, Fryer SL, Meyerhoff DJ: Cortical thickness, surface area, and volume of the brain reward system in alcohol dependence: relationships to relapse and extended abstinence. Alcohol Clin Exp Res 2011;35:11871200. 
45 Hibar DP, Stein JL, Renteria ME, AriasVasquez A, Desrivières S, Jahanshad N, Toro R, Wittfeld K, Abramovic L, Andersson M, Aribisala BS, Armstrong NJ, Bernard M, Bohlken MM, Boks MP, Bralten J, Brown AA, Chakravarty MM, Chen Q, Ching CR, Cuellar-Partida G, den Braber A, Giddaluru S, Goldman AL, Grimm O, Guadalupe T, Hass J, Woldehawariat G, Holmes AJ, Hoogman M, Janowitz D, Jia T, Kim S, Klein M, Kraemer B, Lee PH, Olde Loohuis LM, Luciano M, Macare C, Mather KA, Mattheisen M, Milaneschi Y, Nho K, Papmeyer M, Ramasamy A, Risacher SL, Roiz-Santiañez R, Rose EJ, Salami A, Sämann PG, Schmaal L, Schork AJ, Shin J, Strike LT, Teumer A, van Donkelaar MM, van Eijk KR, Walters RK, Westlye LT, Whelan CD, Winkler AM, Zwiers MP, Alhusaini S, Athanasiu L, Ehrlich S, Hakobjan MM, Hartberg CB, Haukvik UK, Heister AJ, Hoehn D, Kasperaviciute D, Liewald DC, Lopez LM, Makkinje RR, Matarin M, Naber MA, Reese McKay D, Needham M, Nugent AC, Pütz B, Royle NA, Shen L, Sprooten E, Trabzuni D, van der Marel SS, van Hulzen KJ, Walton E, Wolf C, Almasy L, Ames D, Arepalli S, Assareh AA, Bastin ME, Brodaty $\mathrm{H}$, Bulayeva KB, Carless MA, Cichon S, Corvin A, Curran JE, Czisch M, de Zubicaray GI, Dillman A, Duggirala R, Dyer TD, Erk S, Fedko IO, Ferrucci L, Foroud TM, Fox PT, Fukunaga M, Gibbs JR, Göring HH, Green RC, Guelfi S, Hansell NK, Hartman CA, Hegenscheid K, Heinz A, Hernandez DG, Heslenfeld DJ, Hoekstra PJ, Holsboer F, Homuth G, Hottenga JJ, Ikeda M, Jack CR Jr, Jenkinson M, Johnson R, Kanai R, Keil M, Kent JW Jr, Kochunov P, Kwok JB, Lawrie SM, Liu X, Longo DL, McMahon KL, Meisenzahl E, Melle I, Mohnke S, Montgomery GW, Mostert JC, Mühleisen TW, Nalls MA, Nichols TE, Nilsson LG, Nöthen MM, Ohi K, Olvera RL, Perez-Iglesias R, Pike GB, Potkin SG, Reinvang I, Reppermund S, Rietschel M, Romanczuk-Seiferth N, Rosen GD, Rujescu D, Schnell K, Schofield PR, Smith C, Steen VM, Sussmann JE, Thalamuthu A, Toga AW, Traynor BJ, Troncoso J,
Turner JA, Valdés Hernández MC, van't Ent $D$, van der Brug M, van der Wee NJ, van Tol MJ, Veltman DJ, Wassink TH, Westman E, Zielke RH, Zonderman AB, Ashbrook DG, Hager R, Lu L, McMahon FJ, Morris DW, Williams RW, Brunner HG, Buckner RL, Buitelaar JK, Cahn W, Calhoun VD, Cavalleri GL, Crespo-Facorro B, Dale AM, Davies GE, Delanty N, Depondt C, Djurovic S, Drevets WC, Espeseth T, Gollub RL, Ho BC, Hoffmann W, Hosten N, Kahn RS, Le Hellard S, Meyer-Lindenberg A, Müller-Myhsok B, Nauck M, Nyberg L, Pandolfo M, Penninx BW, Roffman JL, Sisodiya SM, Smoller JW, van Bokhoven $H$, van Haren NE, Völzke $H$, Walter $\mathrm{H}$, Weiner MW, Wen W, White T, Agartz I, Andreassen OA, Blangero J, Boomsma DI, Brouwer RM, Cannon DM, Cookson MR, de Geus EJ, Deary IJ, Donohoe G, Fernández G, Fisher SE, Francks C, Glahn DC, Grabe HJ, Gruber O, Hardy J, Hashimoto R, Hulshoff Pol HE, Jönsson EG, Kloszewska I, Lovestone S, Mattay VS, Mecocci P, McDonald C, McIntosh AM, Ophoff RA, Paus T, Pausova Z, Ryten M, Sachdev PS, Saykin AJ, Simmons A, Singleton A, Soininen $\mathrm{H}$, Wardlaw JM, Weale ME, Weinberger DR, Adams HH, Launer LJ, Seiler S, Schmidt R, Chauhan G, Satizabal CL, Becker JT, Yanek L, van der Lee SJ, Ebling M, Fischl B, Longstreth WT Jr, Greve D, Schmidt H, Nyquist P, Vinke LN, van Duijn CM, Xue L, Mazoyer B, Bis JC, Gudnason V, Seshadri S, Ikram MA; Alzheimer's Disease Neuroimaging Initiative; Charge Consortium; Epigen; Imagen; Sys, Martin NG, Wright MJ, Schumann G, Franke B, Thompson PM, Medland SE: Common genetic variants influence human subcortical brain structures. Nature 2015;520:224-229.

46 Bartsch AJ, Homola G, Biller A, Smith SM, Weijers HG, Wiesbeck GA, Jenkinson M, De Stefano N, Solymosi L, Bendszus M: Manifestations of early brain recovery associated with abstinence from alcoholism. Brain 2007;130:36-47.

47 Harper C: The neuropathology of alcohol-related brain damage. Alcohol Alcohol 2009;44: 136-140.
48 Ende G, Welzel H, Walter S, Weber-Fahr W, Diehl A, Hermann D, Heinz A, Mann K: Monitoring the effects of chronic alcohol consumption and abstinence on brain metabolism: a longitudinal proton magnetic resonance spectroscopy study. Biol Psychiatry 2005;58:974-980.

49 Schweinsburg BC, Taylor MJ, Videen JS, Alhassoon OM, Patterson TL, Grant I: Elevated myo-inositol in gray matter of recently detoxified but not long-term abstinent alcoholics: a preliminary MR spectroscopy study. Alcohol Clin Exp Res 2000;24:699705.

50 Köhler S, Klimke S, Hellweg R, Lang UE: Serum brain-derived neurotrophic factor and nerve growth factor concentrations change after alcohol withdrawal: preliminary data of a case-control comparison. Eur Addict Res 2013;19:98-104.

51 White T, Andreasen NC, Nopoulos P, Magnotta V: Gyrification abnormalities in childhood- and adolescent-onset schizophrenia. Biol Psychiatry 2003;54:418-426.

52 Zeng T, Chen H, Fakhry A, Hu X, Liu T, Ji S: Allen mouse brain atlases reveal different neural connection and gene expression patterns in cerebellum gyri and sulci. Brain Struct Funct 2014, Epub ahead of print.

53 Beck A, Wüstenberg T, Genauck A, Wrase J, Schlagenhauf F, Smolka MN, Mann K, Heinz A: Effect of brain structure, brain function, and brain connectivity on relapse in alcoholdependent patients. Arch Gen Psychiatry 2012;69:842-852.

54 Müller-Oehring EM, Jung YC, Pfefferbaum A, Sullivan EV, Schulte T: The resting brain of alcoholics. Cereb Cortex 2014;pii:bhu134.

55 Chanraud S, Pitel AL, Pfefferbaum A, Sullivan EV: Disruption of functional connectivity of the default-mode network in alcoholism. Cereb Cortex 2011;21:2272-2281.

56 Reuter M, Tisdall MD, Qureshi A, Buckner RL, van der Kouwe AJ, Fischl B: Head motion during MRI acquisition reduces gray matter volume and thickness estimates. Neuroimage 2015;107:107-115. 